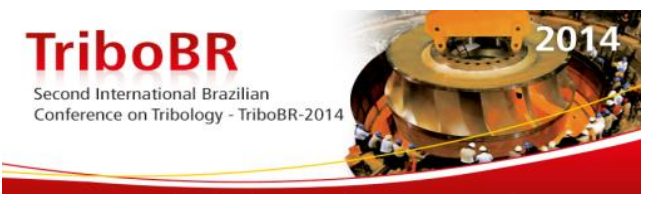

\title{
CONTROL STRATEGIES FOR FRICTION DAMPERS: NUMERICAL ASSESSMENT AND EXPERIEMTAL INVESTIGATIONS*
}

\author{
Humberto Tronconi Coelho' \\ Marcelo Braga dos Santos ${ }^{1}$ \\ Francisco Paulo Lépore Neto ${ }^{1}$
}

\begin{abstract}
The use of friction dampers are wide proposed for a variety of mechanical systems for which it is not possible to apply viscoelastic materials, fluid based dampers or others viscous dampers. An important example is the application of friction dampers in aircraft engines to reduce the blades vibration amplitudes. In most cases, friction dampers have been studied in a passive way, however, a significant improvement can be achieved by controlling the normal force in the contact region. The aim of this paper is to study four control strategies for friction dampers based on three different hysteresis cycles. The first control strategy maximizes the energy removal in each harmonic oscillation cycle, by calculating the optimum normal force based on the last displacement peak. The second control strategy combines the first one with the maximum energy removal strategy used in the smart spring devices. Finally, is presented the strategy which homogenously modulates the friction force. Numerical studies were performed with these four strategies defining the performance metrics. The best control strategy was applied experimentally. The experimental test rig was fully identified and its parameters were used for numerical simulations. The obtained results have shown the good performance for the friction damper and selected strategy, also, the agreement between numerical and experimental results.
\end{abstract}

Keywords: Friction damper; Hysteresis cycle; Semi-active control strategies.

1 Mechanical Systems Laboratory, Mechanical Engineering School, Federal University of Uberlandia, Uberlandia, Minas Gerais, Brazil.

* Technical contribution to the $2^{\text {nd }}$ International Brazilian Conference on Tribology - TriboBR 2014, November $3^{\text {rd }}$ to $5^{\text {th }}, 2014$, Foz do Iguaçu, PR, Brazil. 


\section{INTRODUCTION}

The use of friction dampers has been proposed in a wide variety of mechanical systems for which it is not possible to apply viscoelastic materials, fluid based dampers or others viscous dampers. A first example is the application of friction dampers in aircraft engines to reduce the blades vibration amplitudes [1]. Seismic isolation based on friction was proven be a very useful solution for large civil structures [2]. In most cases, friction dampers had been studied in a passive way, however, a significant improvement can be achieved by controlling the normal force in the dampers [3]. Friction dampers with variable normal force are classified as semi-active devices and their appeal is to have performance levels rivalling the active devices with low level of energy consumption [4]. A brief bibliography review should reveal numerous strategies for control laws in friction damping. Inaudi [5] proposed that the normal force should be proportional to the absolute value of the prior local peak of damper deformation, the author called damper deformation the relative displacement of the degrees of freedom, in which between the damper was installed. The best proportion for the normal force, for a harmonic excitation, was described by Menq [6,7]. Ozbulut et al [8] proposed the use of fuzzy logic to actualize the normal force in semi active friction dampers used for huge civil structures. Yang et al [9] designed a modification for the Inaudi [5] control strategy. This modification actualizes the normal force continuously with the damper deformation. The authors proposed two parameters to adjust their control strategy: Control gain and a boundary layer parameter which means how fast the controller changes the normal force. The aforementioned control strategy demand high levels of control gain, as shown the results obtained by the authors. Nitzsche et al [10] propose a control strategy for system where the friction damper has two states only: "ON" and "OFF". In their strategy, the damper accumulates potential energy, by means of the tangential elastic deformation. Therefore, the damper accumulates energy only when the system goes far from its static equilibrium position, this energy is not restored to the system since the damper is turned off when it moves towards its static equilibrium position. The authors conclude that a passive friction damper can be optimized only for specific excitation forces and system dynamics characteristics. Besides, Vanderborght et al [11] define the challenge as tune the friction dampers to achieve any desired damping characteristics, pointing out the main advantage as the high damping forces even for low velocities.

The aim of this paper is to study three cases of control strategies for friction dampers based on the hysteresis cycle. The first control strategy, named "Case A", maximizes the energy removal in each harmonic oscillation cycle calculating the optimum normal force, i.e., uses the force that maximizes the hysteresis area reducing the vibration amplitude. A second control law, named "Case B", combines the first strategy with the maximum energy removal strategy used in the smart spring devices. Control law namely "Case C" has been proposed by Yang et al [9]. Finally, is presented a modification in the modulated homogeneous friction damper as it has been originally proposed, namely "Case D". Case "D" maintains the hysteresis cycle for case $\mathrm{C}$, changes had been done introducing a predictor for the future speedy. This modification intends to reduce the necessity for large value of Control Gain. The receptance curves for a one degree of freedom coupled to the friction damper are used to evaluate the control strategies performances. All results were obtained by using the time domain integration procedure, called discrete-time state-space formulation, proposed by Lyan-Ywan [12]. Simulations were conducted by using

\footnotetext{
* Technical contribution to the $2^{\text {nd }}$ International Brazilian Conference on Tribology - TriboBR 2014, November $3^{\text {rd }}$ to $5^{\text {th }}$, 2014, Foz do Iguaçu, PR, Brazil.
} 
physical parameters resulting from the identification process of the experimental test rig. The proposed modified control law, case "D", is applied in this test rig and the results are compared with the numerical ones.

\section{THEORETHICAL APPROACH}

The energy dissipation characteristics of a damper can be understood by its hysteresis loop. The hysteresis loop of a variable friction damper depends greatly on the control algorithm applied. In other words, the same variable friction damper with the same excitation may have different hysteretic behaviours when different control algorithms are applied. In this work, all hysteresis curves had been obtained using the friction damper model as presented by Figure 1.

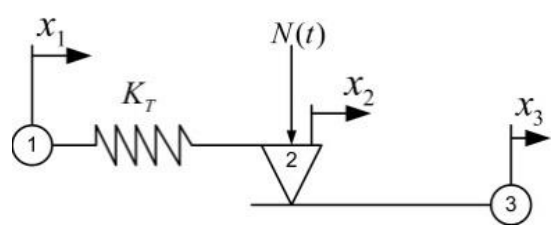

Figure 1. Friction damper model.

For the proposed model the force between NODE $\mathbf{1}$ and NODE $\mathbf{3}$ is written as follow:

$$
F_{13}=\left\{\begin{array}{lll}
K_{T}\left(x_{3}-x_{1}\right) & \text { if } & K_{T}\left(x_{3}-x_{1}\right)<\mu N \\
\operatorname{sign}\left(x_{3}-x_{1}\right) \mu N & \text { if } & K_{T}\left(x_{3}-x_{1}\right) \geq \mu N
\end{array}\right.
$$

It can be observed that the normal force value is the controllable parameter that has influence in damper scenario. Therefore, measuring and controlling the normal force is possible to modify the coupling status and perform the semi-active vibration control. In fact the changes in the coupling will modify the relative displacement between NODE 1 and 3.

Assuming harmonic motion for $\boldsymbol{x}_{\mathbf{1}}(\boldsymbol{t})$, and $\boldsymbol{x}_{\mathbf{3}}(\boldsymbol{t})=\mathbf{0} \forall \boldsymbol{t}$ on Equation (0), the normalized hysteresis cycles for the four studied cases were idealized and presented in the Figure 2.

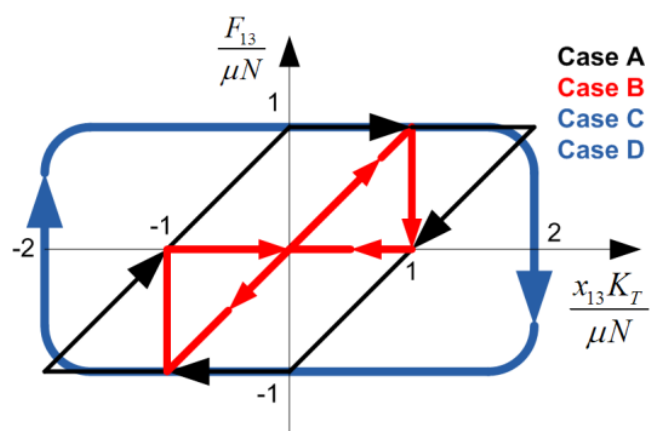

Figure 2. Normalized hysteresis cycle.

Note that cases "C" and " $\mathrm{D}$ " are based on the same hysteresis cycle and differences between them will be described ahead. These hysteresis cycles will be used to damp a 1 DOF (Degree of Freedom) system as it is presented Figure 3. The parameters are: mass $m_{1}=4.274 \mathrm{~kg}$, stiffness $k_{1}=60.5 \mathrm{kN} / \mathrm{m}$, with $c_{1}=33.175 \mathrm{Ns} / \mathrm{m}$ viscous damper. These values correspond to a damping factor of $\xi=3.26 \%$ and a natural frequency $f_{n}=18.94 \mathrm{~Hz}$.

* Technical contribution to the $2^{\text {nd }}$ International Brazilian Conference on Tribology - TriboBR 2014, November $3^{\text {rd }}$ to $5^{\text {th }}$, 2014, Foz do Iguaçu, PR, Brazil. 

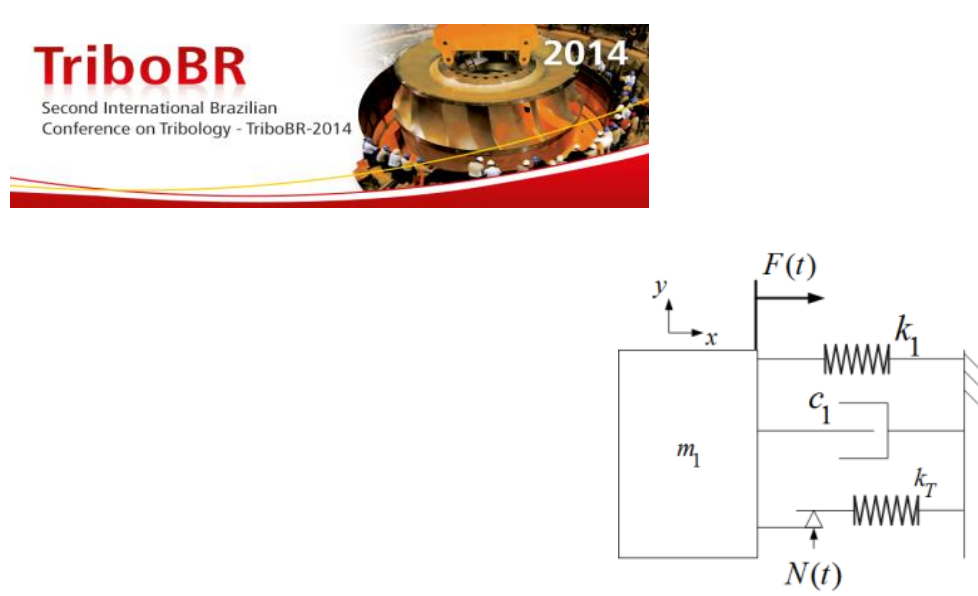

Figure 3. One degree of freedom vibratory system.

These physical parameters, for the linear system, had been identified using the receptance curve measured on the test rig, this receptance curve has been obtained using $\boldsymbol{N}(\boldsymbol{t})=\mathbf{0}$. It is possible to notice a good agreement between the experimental curve and the estimated one (Figure 4).

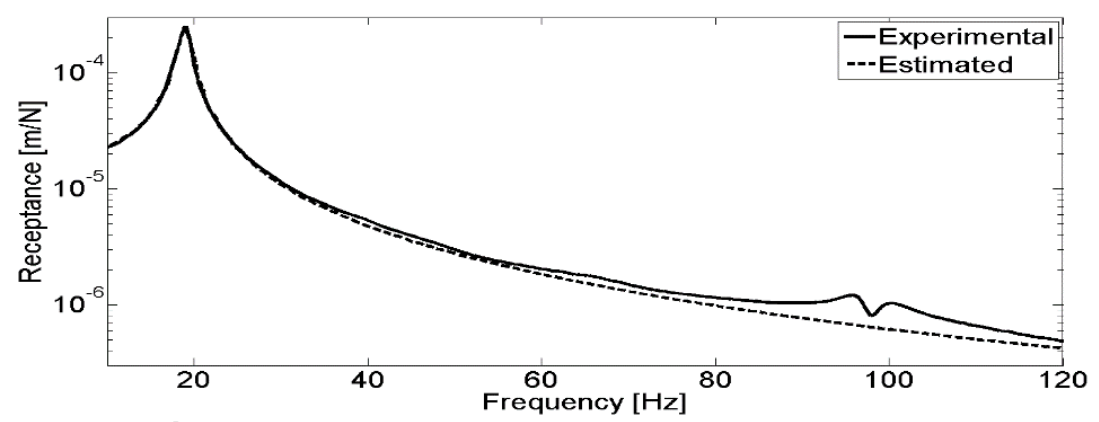

Figure 4. Measured and estimated receptance curve.

Should be noticed the presence of small peaks between 90 and $100 \mathrm{~Hz}$. These peaks are due the test rig setup, which consist of a single base where is attached the 1 DOF vibratory system and the column to support the friction damper. So that, these peaks are due the dynamic behavior of the column, which is flexible instead be perfectly rigid as it is considered in the numerical model.

To identify the contact parameters, harmonic excitation of $20 \mathrm{~N}$ at $19 \mathrm{~Hz}$ was applied to the system. The frequency was chosen as close as possible to the resonant frequency to produce large displacements. These large displacements produce the permanent slippage state on the friction damping. This hysteresis cycle was used to estimate the friction coefficient and the tangential stiffness by means of a curve fitting procedure of Equation Erro! Fonte de referência não encontrada.. On Figure 5 is possible to see that the measurements present some noises especially for negative values of the friction force, ones can observe some differences between two curves close to stick regions due the stick/slip transition in this region which disturbs the measurements.

* Technical contribution to the $2^{\text {nd }}$ International Brazilian Conference on Tribology - TriboBR 2014, November $3^{\text {rd }}$ to $5^{\text {th }}, 2014$, Foz do Iguaçu, PR, Brazil. 


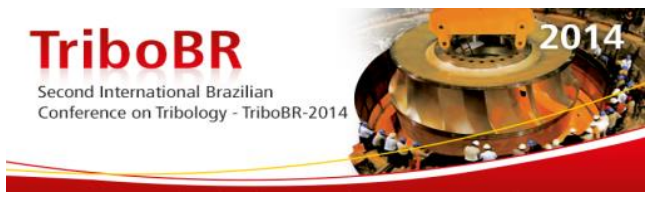

force. The excitation frequency sweep in steps of $0.25 \mathrm{~Hz}$ from $10 \mathrm{~Hz}$ up to $120 \mathrm{~Hz}$ to calculate the receptances. The normal force values imposed in strategies that apply a constant level is $\mathbf{1 0 N}$, and for ones that needs the additional parameters $\boldsymbol{\alpha}$ and $\boldsymbol{\beta}$ the values are $\mathbf{1 0}$ and 20, respectively. These results are shown in Figure 6.

Where NONE means the free vibration receptance. We can observe that the best performance, for those experiment parameters, has been achieved with the control law for "Case A". All control laws has been able to produce a high reduction in the receptance amplitude eliminating the resonance peak. Apparently cases " $C$ " and " $D$ " presents the same receptance. However, Santos and Neto [13] comment that the lowest friction force is obtained with "Case D" control law which can represent a lowest level of contact surfaces wear.

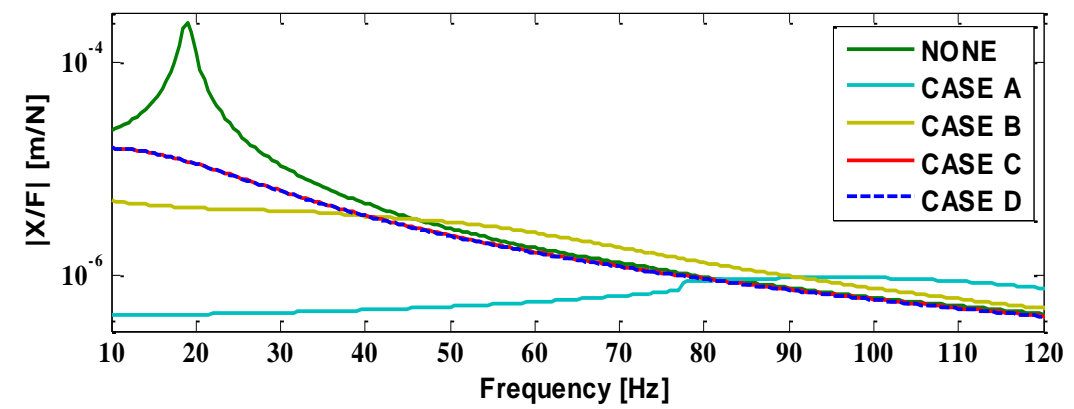

Figure 6. Numerical receptances obtained for the 1 DOF controlled systems.

\section{EXPERIMENTAL RESULTS}

The test rig used to validate the numerical results and to study the friction damper is presented in the Figure 7. In this figure is not presented the computer and the DAQ BOARD used to control the normal force. To control the excitation level, an Agilent Signal Analyser 35670A was used.

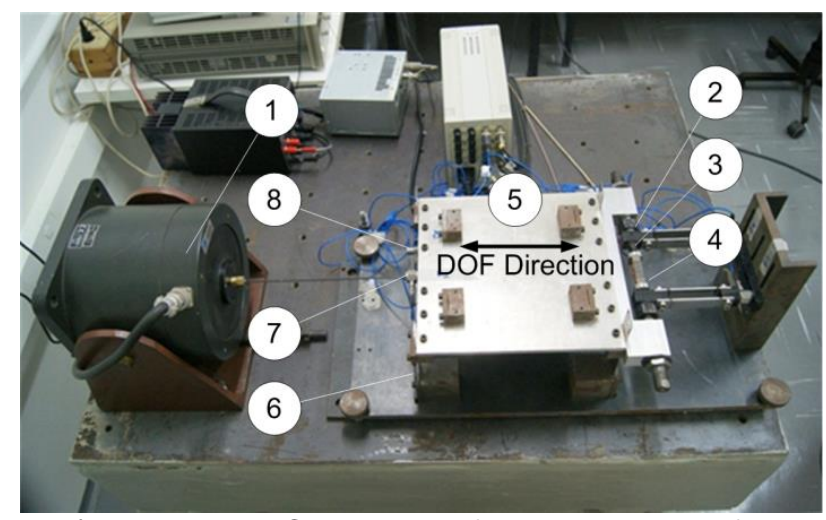

Figure 7. Test rig setup. (1-Exciter, 2-Contact surface, 3-Normal force load cell, 4-Piezelectric actuator, 5-DOF mass, 6-DOF suspension, 7-Excitation load cell and 8-DOF accelerometer)

The contact pair is composed by a sphere and a plane. The fixed parts, describe in the model as (1), are spheres positioned in a special frame which permits control the normal force and a very high rigidity in the DOF direction. The planes are fixed to the DOF using screws which, permit also to adjust the DC level of the normal force.

\subsection{Constant Normal Force Results}

\footnotetext{
* Technical contribution to the $2^{\text {nd }}$ International Brazilian Conference on Tribology - TriboBR 2014, November $3^{\text {rd }}$ to $5^{\text {th }}$, 2014, Foz do Iguaçu, PR, Brazil.
} 


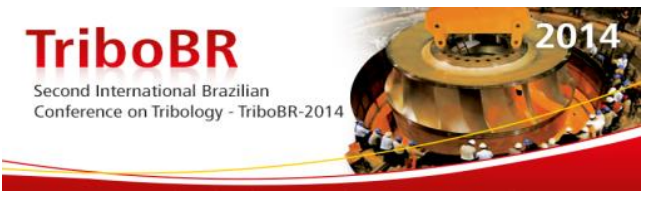

Using this setup, tests with constant normal forces were conducted in order to validate numerical simulations. The results obtained are shown in Figure 8 where $F_{e}$ is the excitation force and $F_{N}$ is the normal force.

Should be noticed the good agreement between numerical and experimental results. The greater difference arises for the black lines. This difference can be due to the errors coming from noise in the instrumentations and also due to the difficulties to measure the displacement at low levels of response. Other important factor that contributes for the small deviations between both curves is the anti-resonance closest to $95 \mathrm{~Hz}$, it can be originated in secondary structures of the test rig, which, has been considered rigid in the model. Besides, the numerical model is representative of the test rig dynamical behavior. Regarding the relation $F_{e} / F_{N}$ the test rig setup has a limitation imposed by the exciter maximum force and the resolution of the control chain for $F_{e}$, i.e., for larger values of $F_{e} / F_{N}$ it is necessary larger values for $F_{e}$ which is limited by the exciter. On the other side, low levels of $F_{e}$ is truncated by the instruments resolution.

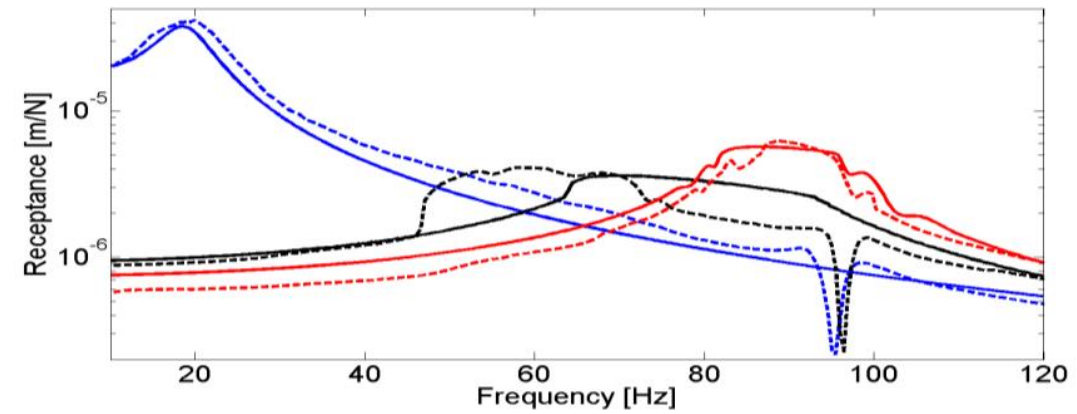

Figure 8. Receptance obtained with constant normal forces. Dashed lines are experimental results and Solid ones are numerical results. $\boldsymbol{F}_{\boldsymbol{e}} / \boldsymbol{F}_{\boldsymbol{N}}$ is equal to 0.1 for red lines, 0.5 for black lines and 2.0 for blue lines.

\subsection{Strategies Results}

After identify the parameters and validate the model, it is possible to evaluate the time response of each strategies control and compare them with the free vibration response. The time response are shown in Figure 9.
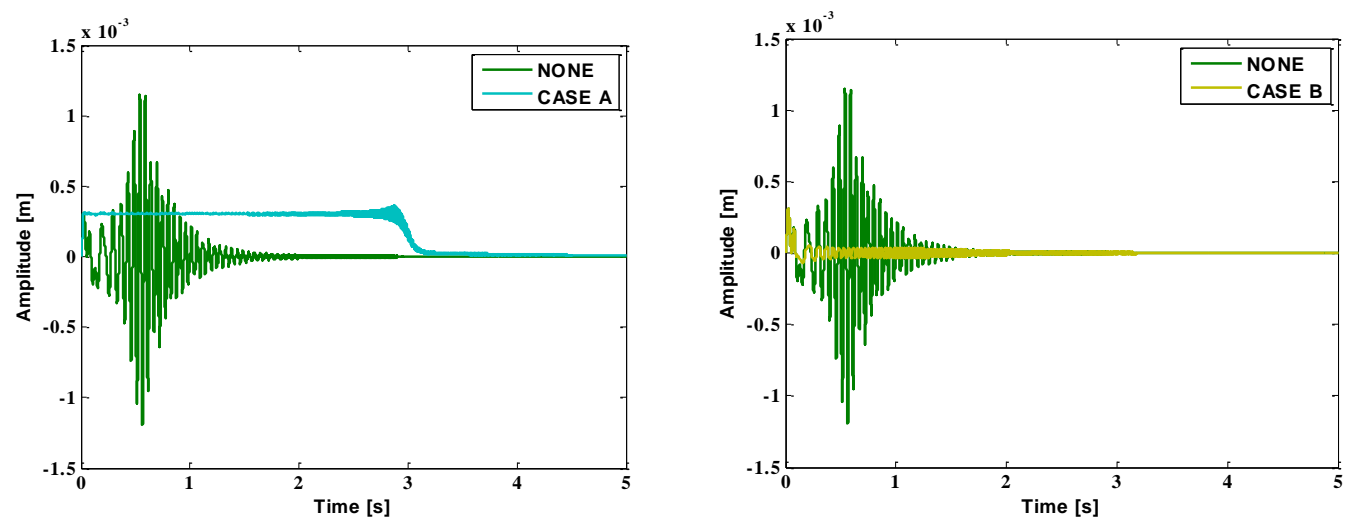

* Technical contribution to the $2^{\text {nd }}$ International Brazilian Conference on Tribology - TriboBR 2014, November $3^{\text {rd }}$ to $5^{\text {th }}$, 2014, Foz do Iguaçu, PR, Brazil. 

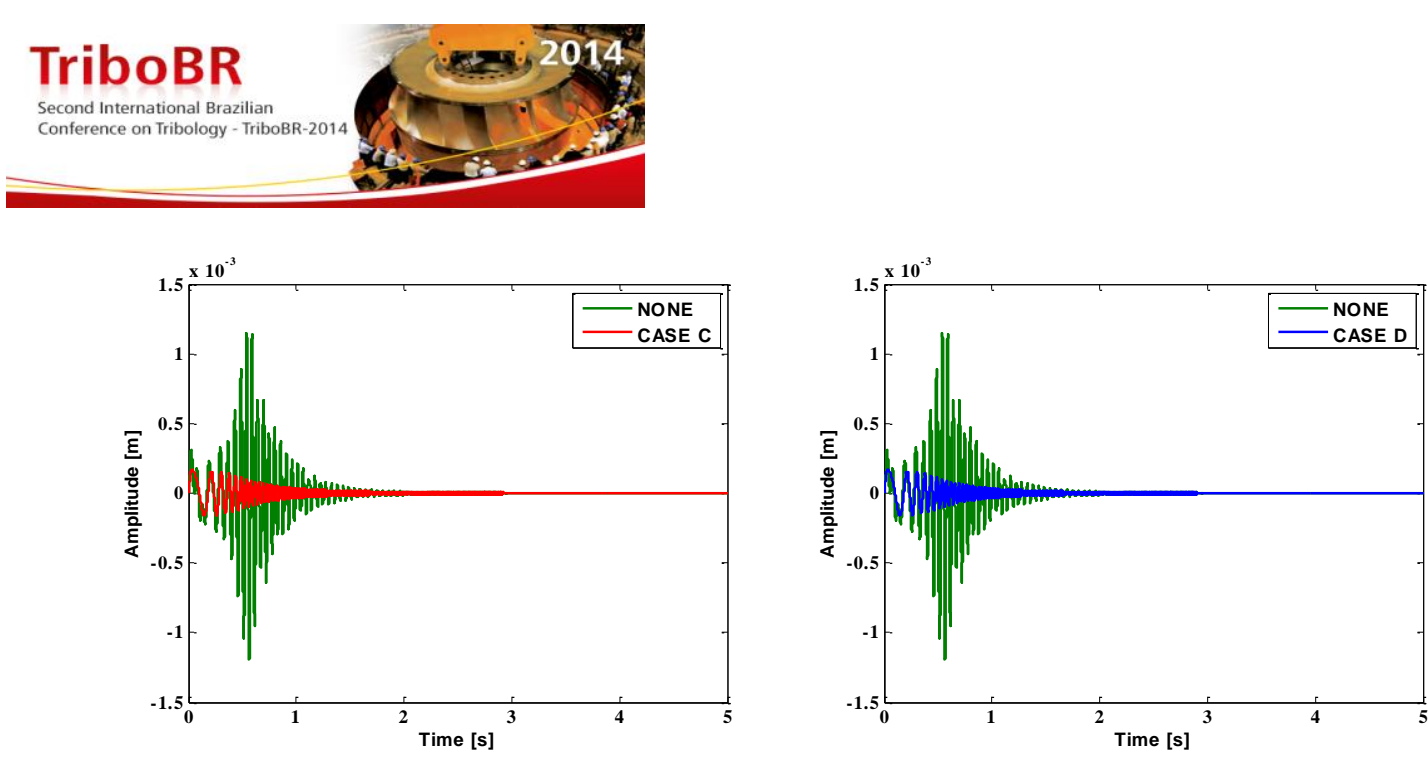

Figure 9. Numerical strategies time responses for a $10 \mathrm{~N}$ excitation force.

It can be observed that for case "A" the coupling stuck at the begin, and the systems oscillates in a position that is not its static equilibrium position for a long time before it returns. All other strategies presented no difficulties to overpass the resonance. And just like on the frequency analysis (Figure 6), case " $C$ " and " $D$ " presents almost the same result.

An indicative of energy consumption, wear rate and control effort can be observed on the normal force demanded for each strategy as shown in Figure 10.
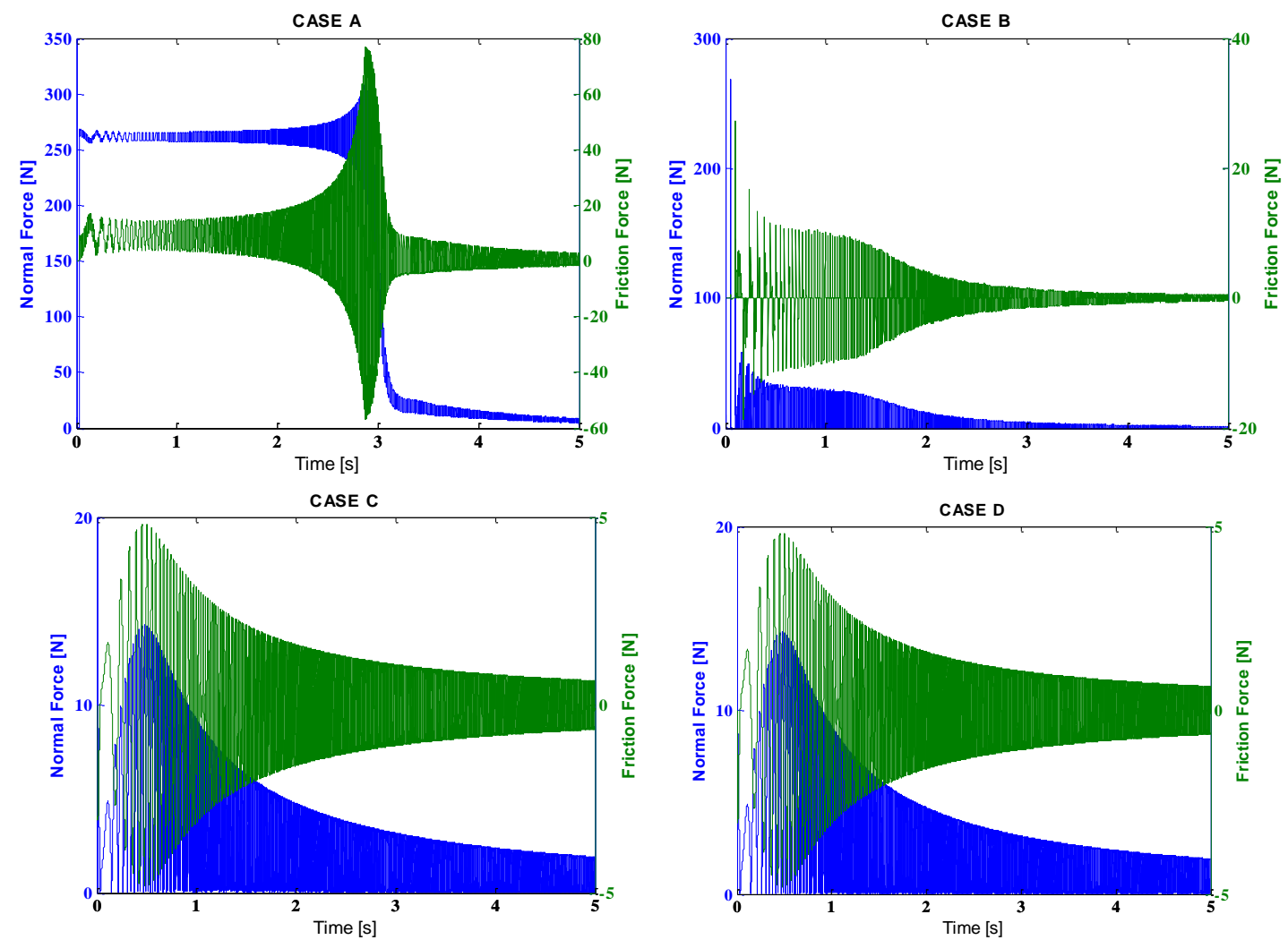

Figure 10. Strategies normal force and friction force for a $10 \mathrm{~N}$ excitation force.

As can be seen the required normal force levels on cases " $C$ " and " $D$ " are smaller than in the others strategies, indicating that the these strategies has a lower energy consumption, consequently lower wear rate if all other trio conditions are hold constant. Again is possible to see that case " $A$ " stuck the coupling, at the most part of the numerical experiment the normal force oscillates around a non-zero value.

* Technical contribution to the $2^{\text {nd }}$ International Brazilian Conference on Tribology - TriboBR 2014, November $3^{\text {rd }}$ to $5^{\text {th }}$, 2014, Foz do Iguaçu, PR, Brazil. 
And experimentally frequency receptances obtained in the test rig are presented in the Figure 11. In that figure the results are compared with the free vibration response.

In this figure it can be observed results very similar to the numerical results (Figure 6). And experimentally is possible to observe that case " $D$ " is a little better than case " $C$ " on resonance region. The attenuation promoted by each strategy compared to the free vibration situation is shown in the Figure 12.

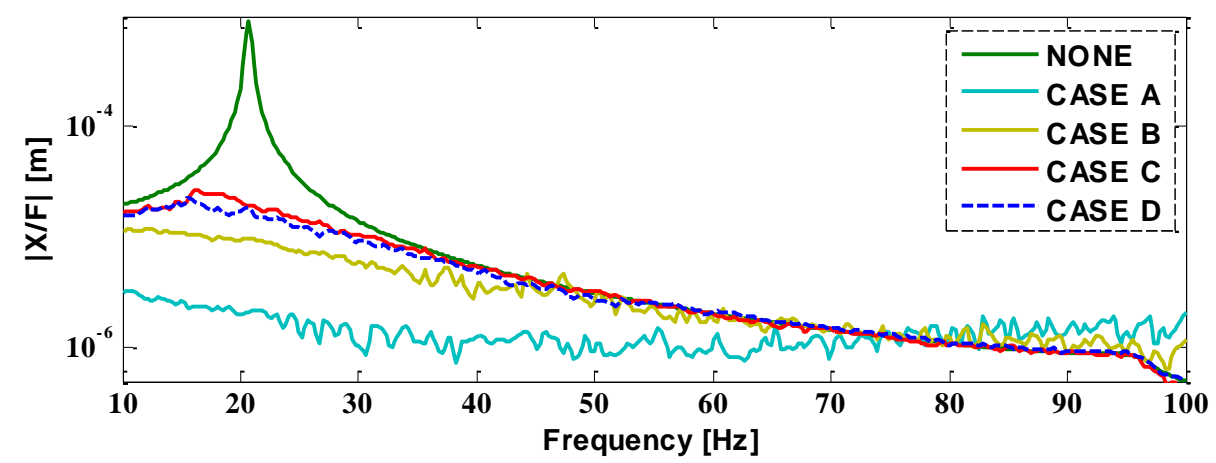

Figure 11. Experimental receptances obtained for the 1 DOF controlled systems.

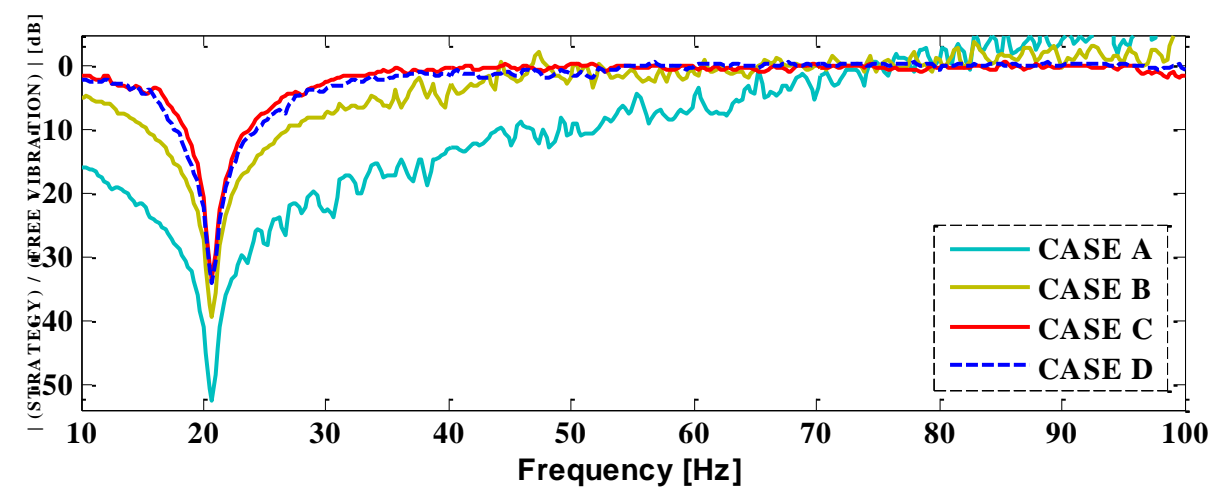

Figure 12. Experimental attenuation of each strategy.

Observe that every strategy attenuates at least $-30 \mathrm{~dB}$ in the resonance peak, and Case "A", that attenuates most, attenuates almost $-55 \mathrm{~dB}$.

Nowadays more important than the attenuation is the efficiency, so at the most practical situation the interest is in achieve a good attenuation with a minimum energy consumption. Therefore, it is necessary a metric to classify each strategy. This metric combines the maximum numerical normal force and the experimental attenuation on the natural frequency peak as shown in the Figure 13.

* Technical contribution to the $2^{\text {nd }}$ International Brazilian Conference on Tribology - TriboBR 2014, November $3^{\text {rd }}$ to $5^{\text {th }}$, 2014, Foz do Iguaçu, PR, Brazil. 

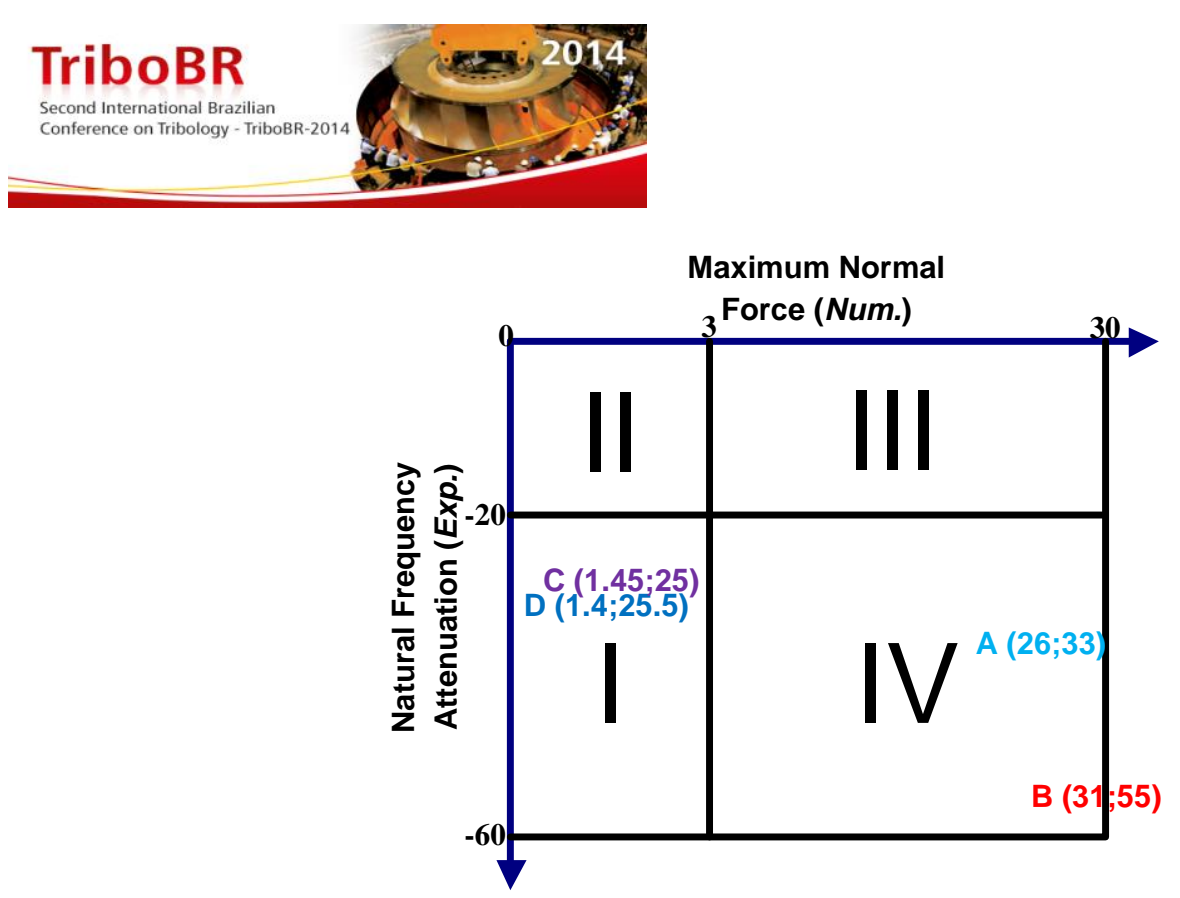

Figure 13. Strategies evaluation metric figure.

Where the quadrant $I$ is considered optimum, once a strategy that is positioned inside it, presents a great attenuation with low level of normal force. Quadrants II and IV are considered little efficient, due to low attenuation level even it demands small values of normal forces or presenting a great attenuation but demand a very high values of normal forces. The last quadrant, namely quadrant III, is considered inefficient once there the strategies present a little attenuation even with high values of normal force demand.

\section{CONCLUSIONS}

The proposed test rig has been fully identified and has been proved useful to study the dynamics of friction damping and the tribological behavior.

Increase the normal force $N(t)$ for a passive damper reduces the resonance peak until a limit, after this limit the impedance will have a new resonance peak due to the parallel association of both stiffness: Tangential Stiffness and Suspension Stiffness.

Control law for Case "C" reduces the resonance peak almost 100 times. Although the resonance peak reduction, this control law has a poor performance. Case " $B$ " and Case "C" had a similar performance. Case "D" control law can be considered as the best control law using the proposed metric. Besides Case "A" presents present the biggest attenuation values it demands high values of normal force, therefore, it is considered little efficient and also stuck the coupling. According the proposed metric, only cases "C" and "D" are considered optimum an applicable for the large majority of application as efficient strategies. It also can be noted that case " $D$ " is the best strategy once its demands lesser energy and presents a higher level of attenuation. Future works will be conducted to optimize the friction damper behavior.

\section{Acknowledgments}

The authors are grateful to the agencies and bureaus which had been supported this research project: Capes, Fapemig and CNPq.

\section{REFERENCES}

* Technical contribution to the $2^{\text {nd }}$ International Brazilian Conference on Tribology - TriboBR 2014, November $3^{\text {rd }}$ to $5^{\text {th }}$, 2014, Foz do Iguaçu, PR, Brazil. 


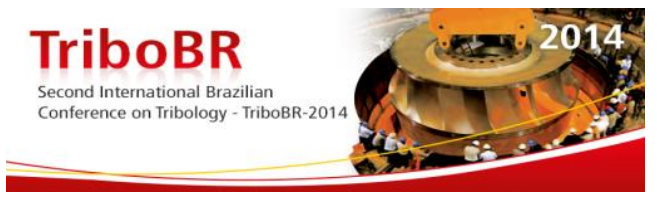

1 Arrao, A.S. and J.G. Nourse, Vibration Damping in Rotor Blades, in UK Patent Application1990, General Electric Company: UK. p. 17.

2 Lu, L.-Y., G.-L. Lin, and T.-C. Kuo, Stiffness controllable isolation system for near-fault seismic isolation. Engineering Structures, 2008. 30(3): p. 747-765.

3 Dupont, P., P. Kasturi, and A. Stokes, Semi-Active Control of Friction Dampers. Journal of Sound and Vibration, 1997. 202(2): p. 203-218.

4 Alvarez-Sánchez, E., A Quarter-Car Suspension System: Car Body Mass Estimator and Sliding Mode Control. Procedia Technology, 2013. 7(0): p. 208-214.

5 Inaudi, J.A., Modulated Homogeneus Friction: A Semi-Active Damping Strategy. Earthquake Engineering \& Structural Dynamics, 1997. 26(3): p. 361-376.

6 Menq, C.H., J.H. Griffin, and J. Bielak, The influence of microslip on vibratory response, Part II: A comparison with experimental results. Journal of Sound and Vibration, 1986. 107(2): p. 295-307.

7 Menq, C.H., J. Bielak, and J.H. Griffin, The influence of microslip on vibratory response, part I: A new microslip model. Journal of Sound and Vibration, 1986. 107(2): p. 279293.

8 Ozbulut, O.E., M. Bitaraf, and S. Hurlebaus, Adaptive control of base-isolated structures against near-field earthquakes using variable friction dampers. Engineering Structures, 2011. 33(12): p. 3143-3154.

9 He, W., A. Agrawal, and J. Yang, Novel Semiactive Friction Controller for Linear Structures against Earthquakes. Journal of Structural Engineering, 2003. 129(7): p. 941-950.

10 Nitzsche, F., et al., Development of a Maximum Energy Extraction Control for the Smart Spring. Journal of Intelligent Material Systems and Structures, 2005. 16(11-12): p. 1057-1066.

11 Vanderborght, B., et al., Variable impedance actuators: A review. Robotics and Autonomous Systems, 2013. 61(12): p. 1601-1614.

12 Lu, L.-Y., et al., Dynamic analysis of structures with friction devices using discrete-time state-space formulation. Computers \&amp; Structures, 2006. 84(15-16): p. 1049-1071.

13 Santos, M.B.d. and F.P. Lepore, Assessment on Control Strategies of Friction Dampers, in Word Tribology Congress 20132013, Associazione Italiana di Tribologia: Turim, Italy.

* Technical contribution to the $2^{\text {nd }}$ International Brazilian Conference on Tribology - TriboBR 2014, November $3^{\text {rd }}$ to $5^{\text {th }}, 2014$, Foz do Iguaçu, PR, Brazil. 